\title{
Visão de gestores municipais sobre requisitos aplicáveis à caracterização de resíduos sólidos urbanos: estudo de caso na Bacia do Paraíba do Sul
}

\section{Vision of municipal managers on requirements applicable to the characterization of urban solid waste: a case study in the Paraíba do Sul Basin}

\author{
Data de entrada: \\ 08/08/2019 \\ - Data de aprovação: \\ $14 / 05 / 2020$
}

Denise Cristina Rodrigues Vieira ${ }^{1}$ | Fabiana Alves Fiore ${ }^{1 *}$

ORCID ID

Vieira DCR (D) https://orcid.org/0000-0002-3014-5564
DOI: https://doi.org/10.36659/dae.2021.062

Fiore FA (D) https://orcid.org/0000-0002-2430-8240

\section{Resumo}

A legislação brasileira estabelece a caracterização dos resíduos sólidos urbanos (RSU) como conteúdo obrigatório dos Planos Municipais de Gestão Integrada de Resíduos Sólidos. No entanto, não determina métodos adequados para a sua realização. Nesse contexto, a presente pesquisa foi realizada com o objetivo de identificar, para o território da bacia do rio Paraíba do Sul, requisitos entendidos como viáveis, pelos gestores públicos municipais, para a composiçãode metodologia unificada de caracterização dos RSU. Os requisitos obtidos a partir de meta-análise foram sistematizados e validados por equipe técnica da agência de bacia e gestores municipais dos estados de SP, RJ e MG. Dentre os resultados obtidos, destacam-se a predileção por: amostragem em zonas de diferentes condições socioeconômicas com frequência anual, determinação de 14 categorias para a composição gravimétrica, a ser realizada por segregação manual de amostras obtidas por meio de quarteamento dos RSU coletados.

Palavras-chave: Resíduos sólidos urbanos. Caracterização. Gestão ambiental.

\section{Abstract}

Brazilian law establishes the characterization of urban solid waste (MSW) as a mandatory content of the Municipal Plans for Integrated Solid Waste Management, however, does not determine appropriate methods for its realization. In this context, the present research was carried out with the objective of identifying, for the territory of the Paraiba do Sul River basin, requirements understood as feasible, by the municipal public managers, for the composition of a unified methodology for the characterization of the MSW. The requirements obtained from the meta-analysis were systematized and validated by the technical team of the basin agency and municipal managers of the states of SP, RJ and MG. Among the results obtained, we highlight the predilection for: sampling in areas of different socioeconomic conditions with annual frequency, determination of 14 categories for the gravimetric composition to be carried out by manual segregation of samples obtained by quartering the collected MSW.

Keywords: Urban solid waste. Characterization. Environmental management.

\footnotetext{
${ }^{1}$ Universidade Estadual Paulista Júlio de Mesquita Filho - São José dos Campos - São Paulo - Brasil.

* Autora correspondente: fabiana.fioreaunesp.br.
} 


\section{INTRODUÇÃO}

O desenvolvimento econômico, a urbanização e o aumento dos padrões de consumo apontam para crescimento na quantidade e complexidade dos RSU em todo o mundo (DIAS et al., 2012). No Brasil, os resíduos sólidos urbanos são definidos como aqueles originários de atividades domésticas em residências urbanas (resíduos domiciliares) somados aos originários nos serviços de limpeza urbana, tais como os de varrição, limpeza de logradouros e vias públicas. A critério dos poderes públicos municipais, a classe de RSU também pode incluir os resíduos gerados nas atividades de serviços e comércios, desde que esses não sejam perigosos e que possuam volume e composição equiparáveis aos resíduos domiciliares (BRASIL, 2010).

Os RSU são formados por componentes de variadas origens e, por isso, apresentam elevada heterogeneidade tanto em relação aos tipos de materiais constituintes como em relação aos seus tamanhos e formas (NASCIMENTO, 2007). De acordo com o IPEA (2012), a média da composição gravimétrica dos 93 estudos realizados entre 1995 e 2008 evidencia que grande parte desses resíduos é constituída de matéria orgânica. O IPEA (2012) também destacou que os dados agregados não foram gerados a partir de metodologia padronizada e que as variações dos indicadores (frequência, escolha da amostra e divisão das categorias) podem levar a dados diferentes da situação real.

Segundo IBAM (2014), a caracterização de RSU consiste na identificação dos tipos de resíduos gerados, incluindo aqueles sujeitos à logística reversa e à caracterização física dos mesmos. Ainda segundo o IBAM (2014), as informações obtidas com a caracterização são fundamentais para a elaboração dos planos de gestão, pois permitem a projeção da geração de resíduos sólidos e o dimensionamento de equipamentos, in- fraestrutura e pessoal para a realização das atividades de manejo.

De acordo com Cruz (2005), a dificuldade da caracterização dos RSU resume-se no fato de que os mesmos têm origem em fontes diversas, fazendo com que os processos que lhes dão origem sejam muito heterogêneos; são produzidos em quantidades não uniformes e possuem soluções de coleta e tratamento distintos. Esses entraves evidenciam a necessidade do estabelecimento de diretrizes que permitam o retratar das diferentes realidades de geração e manejo dos RSU nos territórios.

No Brasil, a caracterização dos RSU é componente mínima dos Planos Municipais de Gestão Integrada de Resíduos Sólidos (PMGIRS). A elaboração dos PMGIRS é uma exigência legal da Política Nacional de Resíduos Sólidos (PNRS) para todos os municípios brasileiros, mesmo que o plano seja realizado de forma simplificada, para os municípios de pequeno porte. A existência do PMGIRS é condição para o acesso dos municípios a recursos da União ou por ela financiados para fins de limpeza pública e manejo de resíduos sólidos (BRASIL, 2010).

Mesmo sendo componente obrigatório dos PMGIRS, não existe metodologia padronizada em nível nacional para a caracterização dos RSU. 0 padrão de amostragem de resíduos sólidos brasileiro, estabelecido pela norma técnica da ABNT (NBR 10007/2004), que define também a précaracterização dos RSU, estabelece que, para resíduos heterogêneos de difícil amostragem e cuja representatividade não puderem ser definida com uma única amostra, como é o caso dos RSU, a escolha do método e do número de amostras caberá aos órgãos estaduais ou federais de controle da poluição e preservação ambiental.

Ainda que não passível de ser integralmente adotada para a caracterização dos RSU, a NBR 10007 ABNT (2004) baliza grande parte dos trabalhos 
desenvolvidos no Brasil. Essa norma estabelece que a pré-caracterização desses resíduos, seja realizada por meio de levantamento dos processos que lhes deram origem. As informações assim obtidas (volume aproximado, estado físico, constituintes principais, temperatura, etc.) permitem a definição do tipo de amostrador mais adequado, dos parâmetros que serão estudados ou analisados, do número de amostras e do seu volume, do tipo de frasco de coleta e dos métodos de preservação que devem ser utilizados.

\subsection{Contexto Territorial}

De acordo com dados da Agência Nacional de Águas (CEIVAP, 2018), a bacia do rio Paraíba do Sul possui área de drenagem de $61.307 \mathrm{~km}^{2}$, e está inserida numa das regiões mais desenvolvidas do país. Abrange parte dos estados de São Paulo (na região conhecida como Vale do Paraíba Paulista), de Minas Gerais (região da Zona da Mata Mineira) e metade do estado do Rio de Janeiro. Nessa bacia estão inseridos 184 municípios, com população urbana total de oito milhões de habitantes (IBGE, 2010). Essa população se distribui nos estados de Rio de Janeiro, Minas Gerais e São Paulo em 43,5\%, 33,2\% e $23,3 \%$, respectivamente.

A gestão da bacia hidrográfica do rio Paraíba do Sul é realizada pelo Comitê da Bacia do rio Paraíba do Sul - CEIVAP, que tem como entidade executora a Associação Pró-Gestão das Águas da Bacia Hidrográfica do Rio Paraíba do Sul (AGEVAP). Nessa bacia ocorre a cobrança pelo uso da água, e esses recursos são importantes promotores de projetos na bacia que visam à melhoria de qualidade de suas águas.

Considerando que a gestão inadequada dos resíduos sólidos possui impacto direto na qualidade dos recursos hídricos, a AGEVAP publicou, em 2013, o edital de chamamento público $\mathrm{N}^{\circ} 02$ objetivando selecionar municípios inseridos total ou parcialmente na bacia hidrográfica do rio Paraíba do Sul, interessados em ter os seus PMGIRS elaborados por empresa contratada pela AGEVAP, com financiamento da Caixa Econômica Federal. Além de assegurar os recursos, a AGEVAP publicou um manual de referência para a elaboração dos PMGIRS e encaminhou comunicação registrada a todos os municípios aptos à captação dos recursos.

Houve baixa adesão dos municípios ao chamamento realizado em 2013, mas o objetivo de elaboração dos PMGIRS dos municípios da bacia foi novamente inserido no Plano de Aplicação Plurianual da Bacia Hidrográfica do Rio Paraíba do Sul - PAP, por meio da Deliberação CEIVAP $n^{\circ}$ 237/2016. A partir de 2017, a AGEVAP, por meio da Escola de Projetos, responsabilizou-se diretamente pela elaboração do PMGIRS de alguns dos municípios da bacia, contribuindo para o desenvolvimento sustentável desses municípios, bem como os auxiliando na possibilidade de obter recursos para área de resíduos sólidos no futuro.

A evidente necessidade de pesquisas metodológicas sobre a temática, visando à normatização das atividades no território da bacia hidrográfica, garantiu a essa pesquisa o apoio logístico da AGEVAP, para o alcance de seu objetivo principal, que foi o de identificar os requisitos que devem compor a metodologia unificada de caracterização dos RSU para os municípios pertencentes à bacia do rio Paraíba do Sul, na visão dos gestores públicos municipais.

\section{METODOLOGIA}

Essa pesquisa aplicada qualitativa iniciou suas atividades com uma meta-análise, por meio da qual foram identificados parâmetros e requisitos já adotados em metodologias de caracterização dos RSU (GERHARDT; SILVEIRA, 2009). A pesquisa 
abarcou os documentos públicos legais, periódicos de grande circulação, bibliotecas universitárias e bancos de dados científicos, publicadas no período de trinta anos (1988 - 2018). Dentre os trabalhos existentes, foram pré-selecionados para avaliação aqueles cujos conteúdos abordavam de forma detalhada os procedimentos metodológicos para caracterização de resíduos sólidos urbanos. Essa e as demais etapas metodológicas são mostradas na Fig. 1.

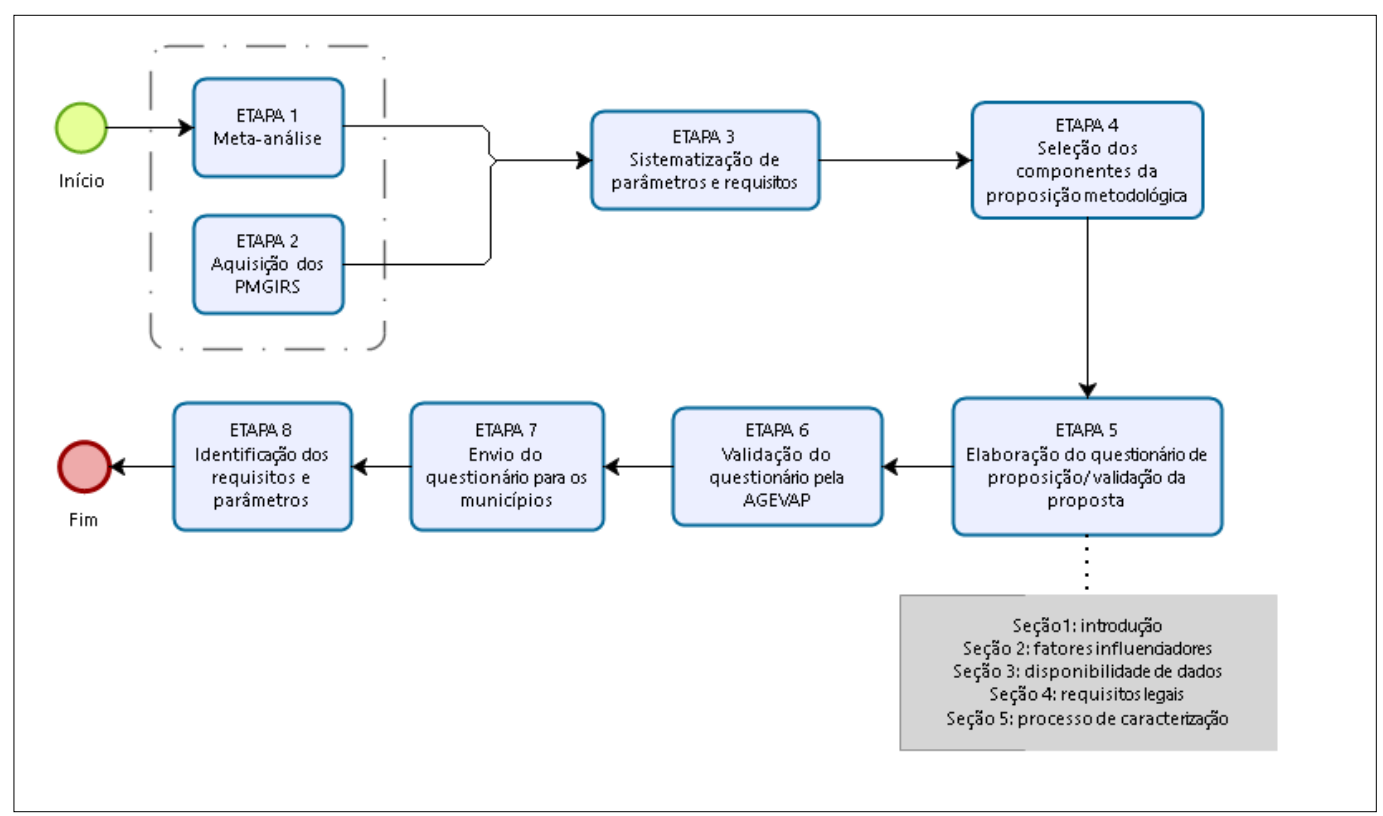

Figura 1 - Representação da metodologia adotada no presente trabalho.

A segunda etapa consistiu na aquisição digitalizada dos PMGIRS publicados nos sítios eletrônicos de cada um dos municípios inseridos na bacia do Rio Paraíba do Sul, a fim de obter metodologias de caracterização base para identificar os parâmetros adotados, a representatividade das amostras, a periodicidade da caraterização, entre outros.

Com os dados das etapas 1 e 2 realizou-se a sistematização dos requisitos e parâmetros de caracterização de RSU e, por critério de legalidade, objetividade, exequibilidade e suficiência, foram selecionados o conjunto de requisitos para composição do questionário da pesquisa (CALIJURI; CUNHA, 2013).

Esse conjunto de requisitos foi levado à equipe técnica da AGEVAP para validação preliminar e pos- teriormente foi encaminhado às secretarias dos municípios inseridos na bacia do rio Paraíba do Sul, como entrevista estruturada do tipo Survey. Para a realização da pesquisa com os gestores locais foi elaborada uma plataforma eletrônica (google docs) visando garantir a agilidade das respostas e das análises estatísticas de seus resultados. 0 mailing dos endereços eletrônicos dos grupos respondentes da pesquisa foi disponibilizado pela AGEVAP e mobilizado a partir do encaminhamento de carta convite e disponibilização do link da plataforma eletrônica (FREITAS et al., 2000).

O questionário enviado aos municípios foi dividido em 5 seções, a primeira delas contendo uma breve explicação sobre a proposta do projeto e o conceito e a importância da caracterização dos RSU. Foi dado conhecimento aos mesmos de que as respostas obtidas, por meio dos questioná- 
rios, serviriam como parte da validação da proposta metodológica. Além disso, houve coleta de dados dos respondentes ao questionário, tais como: município de pertencimento, e-mail, formação e cargo atual.

A seção 2 inqueriu os municípios sobre quais fatores (provenientes de pesquisas estatísticas ou panoramas fornecidos pelo IBGE) poderiam influenciar na geração e composição de seus RSU em seus territórios, tais como: densidade demográfica, ocupação territorial, economia, saúde, manejo dos resíduos, existência de turismo e eventos no município, entre outros. Além disso, esta seção requereu que os gestores municipais atribuíssem graus de importância (de 0 a 5) entre os fatores identificados na meta-análise e a composição e geração dos RSU, em seus territórios (SILVA, 2008). Os fatores disponibilizados para seleção foram: sazonalidade; períodos festivos; existência de datas comemorativas e eventos culturais; diferentes culturas e hábitos de vida; diferentes tecnologias de tratamento de RSU; coleta e destinação dos RSU; localização geográfica territorial; condições socioeconômicas; grau de industrialização; diferentes setores econômicos preponderantes e a realização da pré-caracterização dos RSU. Para a qualificação dessa significância o intervalo foi dividido linearmente em três patamares, sendo: de 0 a 1 considerado como BAIXA significância de 2 a 3 como MÉDIA e de 4 a 5 como ALTA.

A seção 3 solicitou que os gestores municipais evidenciassem quais dados já estavam disponíveis, em seus territórios, para subsidiar a caracterização dos RSU. Esses dados referem-se aos fatores citados na seção 2 e são utilizados para a determinação de elementos prévios à caracterização, na medida em que permitem a definição mais precisa da representatividade das amostras de RSU a serem caracterizadas, bem como seu comportamento em nível espacial e temporal no município.
A seção 4 referia-se, especificamente, ao atendimento dos requisitos legais relacionados ao manejo dos RSU por parte dos municípios e incluiu: a realização da coleta seletiva nas diferentes atividades (domicílios, varrição urbana, comércio e serviço) exclusivamente para a área urbana, segundo preconiza a PNRS. Essa seção também viabilizou que os municípios informassem se realizavam a coleta dos RSU secos e úmidos separadamente, conforme preconiza o decreto 7404/2010. O cumprimento desses requisitos legais, que garantem a identificação das fontes geradoras, facilita os processos de caracterização dos resíduos e a atribuição de responsabilidades pelo manejo.

Por fim, a quinta e última seção abordou o processo de caracterização dos RSU propriamente ditos e inquiriu os municípios sobre a existência de recursos para elaboração do plano de amostragem (conforme recomenda NBR 10007:2004). Solicitou-se também que os gestores municipais escolhessem, a partir da especificidade local, quais tipos de amostradores seria possível utilizar; em qual(is) ponto(s) deveria(m) ser coletado(as) suas amostras de RSU; qual o tamanho das unidades de amostragem; qual a preparação de amostragem adequada; quais tipos e formas de recipientes de amostragem; em quais unidades territoriais a coleta dos RSU deveria ser dividida.

Também inquiriu-se sobre a adequada frequência de repetição das campanhas de caracterização; quais períodos deveriam ser considerados como uma campanha; qual número de dias de seleção de amostras; quais métodos de triagem o município possui recursos para realizar; em quais categorias é possível que o município separe os RSU na triagem; quais recursos mecânicos e pessoais o município tem disponível para caracterização; quais equipamentos de segurança já estão disponíveis e, por fim, quais dos parâmetros físicos, químicos e biológicos o município 
acreditava ser importante para as análises de caracterização dos RSU.

A sistematização e análise dos dados obtidos foram realizadas de forma específica para cada uma das seções da pesquisa, com o uso de planilhas eletrônicas. Os resultados foram equiparados e discutidos a partir da análise dos dados públicos relativos à gestão de RSU no território em estudo.

\section{RESULTADOS}

Os resultados da meta-análise realizada estão mostrados nas Tabelas 1, 2 e 3. Para sua construção foram utilizadas as seguintes palavraschave compostas: metodologia caracterização resíduos sólidos urbanos; metodologia caracterização resíduos sólidos; caracterização resíduos sólidos urbanos; caracterização de resíduos; re- síduos sólidos urbanos e resíduos sólidos. As bases de dados consultadas foram:

1. Bases estaduais: secretarias estaduais de meio ambiente e assembleias legislativas dos três estados (MG, RJ e SP);

2. Bases federais: planalto, Conama, IBAMA e Ministério do Meio Ambiente;

3. Bases municipais: PMGIRS;

4. Bases acadêmicas: Science Direct e Scopus;

5. Bases de universidades: Unesp, USP, Unicamp, UFRJ, UFMG;

6. Bases de revistas: Waste management e ABES.

Todos os trabalhos que abordaram procedimentos metodológicos para caracterização de resíduos sólidos foram selecionados para a pesquisa.

Tabela 1 - Levantamento bibliográfico - Principais Universidades Públicas da bacia.

\begin{tabular}{|c|c|c|c|c|}
\hline & $\begin{array}{l}\text { Programa De Pós- } \\
\text { Graduação }\end{array}$ & Trabalhos (1988-2018) & $\begin{array}{l}\text { Dissertações Mestrado } \\
\text { Pré-Selecionadas }\end{array}$ & $\begin{array}{c}\text { Teses } \\
\text { Pré- Selecionadas }\end{array}$ \\
\hline \multirow{4}{*}{$\begin{array}{l}\text { UNESP } \\
135.515\end{array}$} & $\begin{array}{l}\text { Agronegócio e } \\
\text { Desenvolvimento }\end{array}$ & 48 & 1 & 0 \\
\hline & $\begin{array}{c}\text { Engenharia Civil e } \\
\text { Ambiental }\end{array}$ & 115 & 1 & 0 \\
\hline & Agronomia & 4343 & 1 & 0 \\
\hline & Engenharia Civil & 217 & 2 & 0 \\
\hline \multirow{4}{*}{$\begin{array}{l}\text { UNICAMP } \\
7.103\end{array}$} & Engenharia Civil & - & 1 & 1 \\
\hline & Engenharia Mecânica & - & 0 & 1 \\
\hline & $\begin{array}{c}\text { Engenharia Civil, } \\
\text { Arquitetura e Urbanismo }\end{array}$ & - & 0 & 1 \\
\hline & $\begin{array}{l}\text { Engenharia Hidráulica e } \\
\text { Saneamento }\end{array}$ & - & 1 & 0 \\
\hline \multirow{3}{*}{$\begin{array}{l}\text { USP } \\
199\end{array}$} & Meio Ambiente & 60 & 1 & 0 \\
\hline & Geotecnia & 15 & 2 & 0 \\
\hline & $\begin{array}{l}\text { Engenharia Hidráulica e } \\
\text { Saneamento }\end{array}$ & 35 & 1 & 0 \\
\hline $\begin{array}{l}\text { UFRJ } \\
328\end{array}$ & Engenharia Civil & 54 & 1 & 0 \\
\hline $\begin{array}{c}\text { UFMG } \\
184\end{array}$ & Engenharia Civil & 54 & 1 & 0 \\
\hline
\end{tabular}


Tabela 2 - Levantamento bibliográfico - Documentos Públicos Legais

\begin{tabular}{|c|c|c|c|c|c|c|}
\hline $\begin{array}{c}\text { DOCUMENTOS/ } \\
\text { LEGISLAÇÃO }\end{array}$ & \multicolumn{2}{|c|}{ Governo Federal } & \multicolumn{2}{|c|}{ Governo Estadual } & \multicolumn{2}{c|}{ Governo Municipal } \\
\hline Leis & Total & Pré-Selecionados & Total & Pré-Selecionados & Total & Pré-Selecionados \\
\hline Decretos & 2 & 1 & 3 & 3 & 0 & 0 \\
\hline Resoluções & 2 & 1 & 0 & 0 & 0 & 0 \\
\hline Normas & 0 & 0 & 0 & 0 & 0 & 0 \\
\hline Planos & 1 & 2 & 0 & 0 & 52 & 0 \\
\hline Instruç̃̃es & 0 & 1 & 2 & 2 & 0 & 0 \\
\hline Normativas & 0 & 0 & 0 & 0 & 0 & 0 \\
\hline Programas & 1 & 0 & 0 & 0 & 0 & 0 \\
\hline Manuais & 0 & 1 & 0 & 0 & 0 & 0 \\
\hline Textos/Documentos & 0 & 0 & 0 & & 0 \\
\hline
\end{tabular}

Tabela 3 - Levantamento bibliográfico - Principais Bases de Dados Científicas

\begin{tabular}{|c|c|c|c|}
\hline & Área & Trabalhos (1988-2018) & $\begin{array}{c}\text { Trabalhos } \\
\text { Pré-Selecionados }\end{array}$ \\
\hline \multirow{6}{*}{ SCOPUS } & Ciências Ambientais & 5 & 0 \\
\hline & Agricultura & 3 & 0 \\
\hline & Química & 1 & 0 \\
\hline & Ciências & 1 & 0 \\
\hline & Engenharia & 1 & 0 \\
\hline & Ecologia & 1 & 1 \\
\hline \multirow{6}{*}{$\begin{array}{c}\text { Science Direct - } \\
\text { Waste Management } \\
77.218\end{array}$} & Outras Ciências & 2718 & 0 \\
\hline & Engenharia Química & 2245 & 1 \\
\hline & Materiais Perigosos & 2693 & 0 \\
\hline & Gerenciamento de Resíduos & 2084 & 6 \\
\hline & Ciências Ambientais & 7121 & 0 \\
\hline & Combustíveis & 1193 & 0 \\
\hline $\begin{array}{c}\text { ABES } \\
2\end{array}$ & Gestão de Resíduos Sólidos & 2 & 1 \\
\hline
\end{tabular}

Os resultados da meta-análise evidenciam que poucas são as pesquisas realizadas sobre a temática no Brasil e no mundo. Devido ao reconhecimento e à maior disponibilidade de informações técnicas, as metodologias destacadas para essa pesquisa foram: D523 (ASTM, 2003); SWA-TOOL (CE, 2004); DGQQA (DGQA, 1989) e Metodologia Simplificada de caracterização de resíduos sólidos urbanos para municípios do Estado de Minas Gerais (FEAM, 2015).
A busca por metodologias de caracterização dos RSU adotadas nos PMGIRS elaborados para a área em estudo mostrou que até 2018 apenas $26 \%$ dos municípios da bacia disponibilizaram publicamente seus planos. Esses dados convergem com aqueles publicados na Pesquisa de Informações Básicas Municipais - MUNIC do IBGE em 2013, sendo que, conforme mostrado na Fig. 2, quase a metade dos 48 PMGIRS disponíveis no território pertenciam a municípios do estado do Rio de Janeiro (MMA, 2018; IBGE, 2013). 


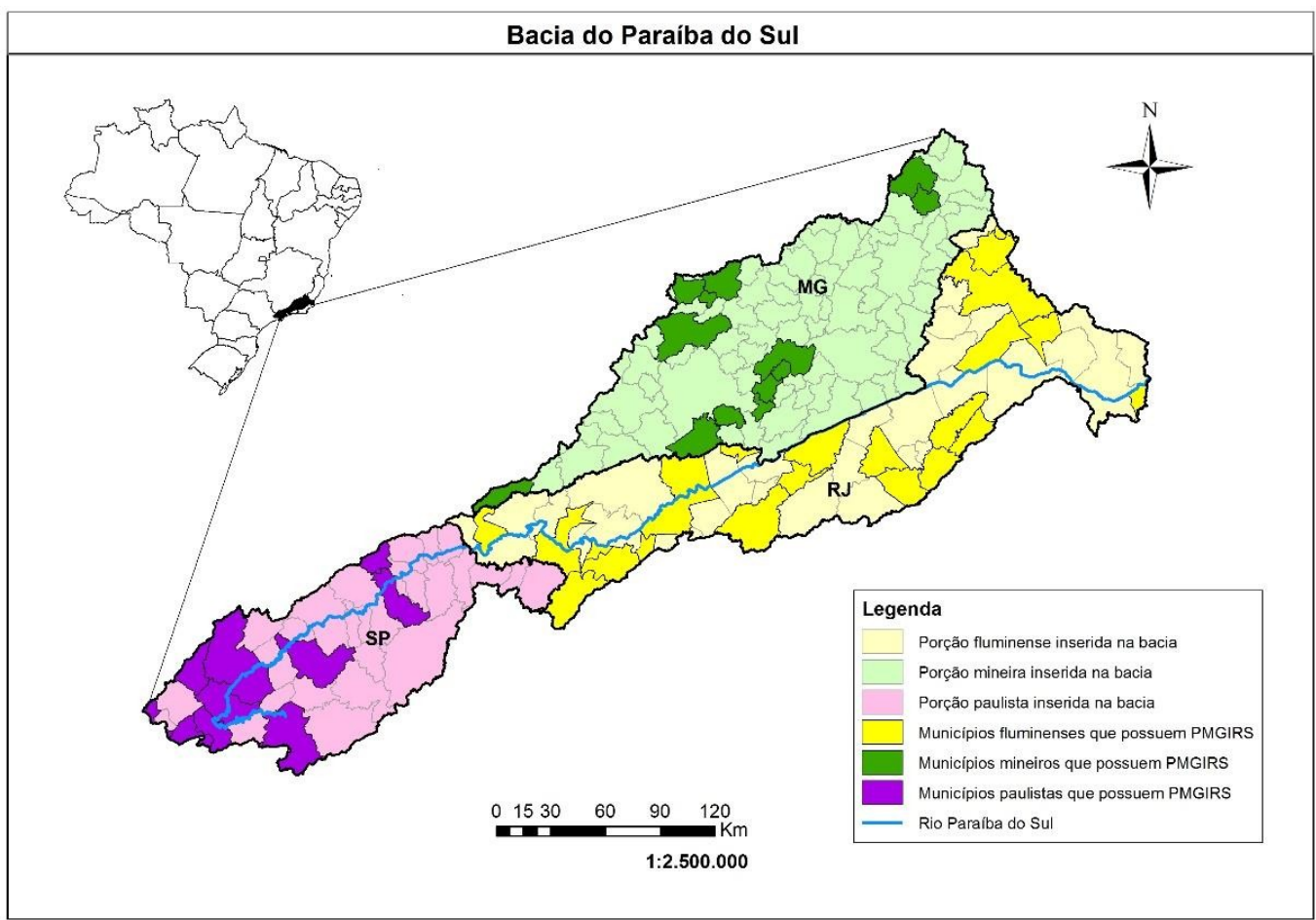

Figura 2 - Mapa dos Municípios pertencentes à bacia do rio Paraíba do Sul que possuem PMGIRS. Fonte: Unesp, 2019.

A partir da análise dos planos disponíveis, verificou-se que em apenas três deles havia dados de caracterização, exclusivamente física (composição gravimétrica), dos RSU, a saber: os municípios de Jacareí (SP), Igaratá (SP) e Rio Preto (MG). Os PMGIRS de Jacareí e Igaratá (SP) não evidenciaram a metodologia adotada para a caracterização de seus resíduos, apenas apresentaram os seus resultados. Em Jacareí, a própria Secretaria do Meio Ambiente realizou as atividades, e em Igaratá apenas os resíduos sólidos domiciliares (RSD) foram amostrados. O município de Rio Preto (MG) apresentou dados sobre as atividades de caracterização física de seus RSD e esses, inclusive, foram utilizados em PMGIRS de outros municípios mineiros (PMGIRS IGARATÁ, 2012; PMGIRS RIO PRETO, 2014; PMGIRS JACAREÍ, 2017).

Consideradas as metodologias avaliadas, foram identificados os critérios que interferem na representatividade estatística da caracterização dos RSU. Dentre eles estão: o volume e o peso das amostras; a distribuição temporal da amostragem; as condições geográficas do território; o tipo de coleta adotado na amostragem; a devida associação das condições socioeconômicas às amostras; a identificação dos períodos típicos de sazonalidade; o tipo de quarteamento adotado durante a amostragem.

Dentre os parâmetros a serem considerados para a amostragem de RSU retratados pelo referencial pesquisado, os mais recorrentes foram o peso específico; a geração per capita e a gravimetria. Também foram identificados os parâmetros: potencial de biodegradabilidade; $\mathrm{pH}$; relação $\mathrm{C}: \mathrm{N}$; teor de matéria orgânica; poder calorífico; compressividade e teor de umidade.

Todos os critérios de representatividade estatística e de parâmetros a serem considerados para a amostragem, identificados no referencial bibliográfico e nos PMGIRS, foram utilizados para 
a construção do questionário estruturado e figuraram como opções apropriadas para a realização das atividades.

\subsection{Subsídios à proposição de Metodologia Regional}

O questionário estruturado foi validado com técnicos da AGEVAP em janeiro/2019. Ainda no mesmo mês também foi encaminhado, em arquivo digital, aos gestores públicos dos 184 municípios pertencentes à área de estudo, com carta de recomendação da Agência. Apenas 35 municípios responderam ao questionário; no entanto, se considerados os apontamentos de Yin (2016), um número de respondentes superior a 25 , para pesquisas qualitativas, pode ser considerado adequado, pois, devido à complexidade do tema, o tipo de setor que está respondendo ao questionário é mais relevante do que a quantidade de respondentes.

Dos 35 municípios respondentes, 10 pertenciam ao estado do Rio de Janeiro, 14 ao de Minas Gerais e 11 ao de São Paulo. Assim sendo, todos os estados foram representados no trabalho. Em $71 \%$ do total de municípios, o representante respondente ao questionário foi um profissional que atua no setor do meio ambiente da prefeitura municipal; $2,85 \%$ representavam o setor da agricultura; $2,85 \%$ o setor administrativo e os demais não tiveram seus setores identificados. 0 perfil dos respondentes evidencia que os dados obtidos por esse trabalho podem ser considerados adequados ao fim proposto.

O percentual de municípios respondentes que entendem como alto o grau de correlação entre os fatores socioeconômicos e a geração e composição dos RSU em seus territórios está mostrado na Fig. 3. Verificou-se também que 97,2\% das respostas obtidas apontaram ser o número da população o principal responsável pela geração e composição dos RSU. O tipo de manejo dos RSU; a ocupação territorial; a localização da área na unidade territorial; as condições de esgotamento sanitário, de urbanização e da gestão do saneamento básico também foram fatores relacionados pelos municípios como capazes de influenciar a geração e composição dos RSU.

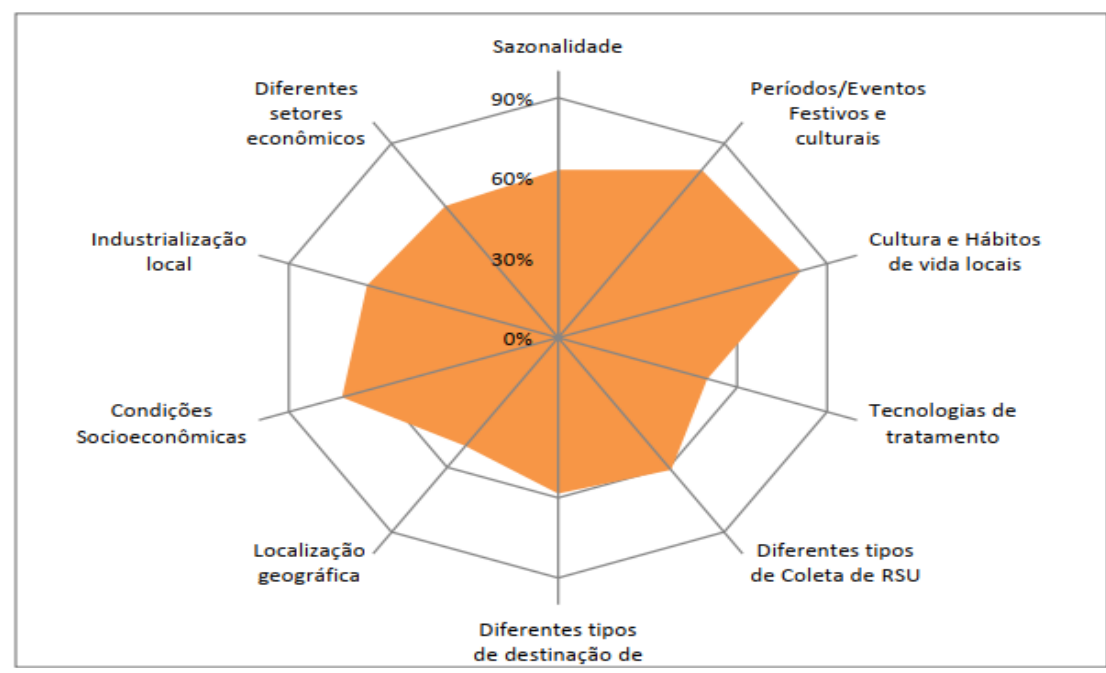

Figura 3 - Porcentagem de municípios que consideram alto o grau de importância dos fatores com a geração de RSU. 
Considerado que todos os parâmetros socioeconômicos apontados pela bibliografia foram reconhecidos como de alta importância para mais de $50 \%$ dos municípios do território em estudo, verifica-se que a percepção dos gestores públicos sobre a temática é convergente com os referenciais metodológicos já existentes (ASTM, 1992; CE, 2004; DGQA, 1989; FEAM, 2015). Destaca-se que a percepção dos gestores pode ser atestada por meio da realização de projeto piloto de caracterização para avaliar as possíveis correlações estatísticas porventura existentes no território. Em caso de operacionalização, sugere-se que os trabalhos sejam iniciados considerados os requisitos reconhecidos como de maior importância pelos gestores locais, a saber: Cultura e Hábitos de Vida Locais;
Períodos/Eventos Festivos e Culturais e Condições Socioeconômicas.

A Fig. 4 mostra o percentual de municípios que informam possuir dados socioeconômicos aptos a serem empregados na caracterização dos RSU. Por meio das respostas obtidas, é possível verificar que poucas informações são consideradas como existentes nos territórios locais, apesar da disponibilidade de dados públicos e privados acerca desses territórios, tais como SNIS, ABRELPE, IBGE. Para suprir tal demanda, o uso de sistema eletrônico integrativo de dados secundários públicos, que permita o acréscimo de declarações locais com maior frequência e detalhamento, pode viabilizar a geração de informações de base para a realização dos diagnósticos desses municípios com maior confiabilidade.

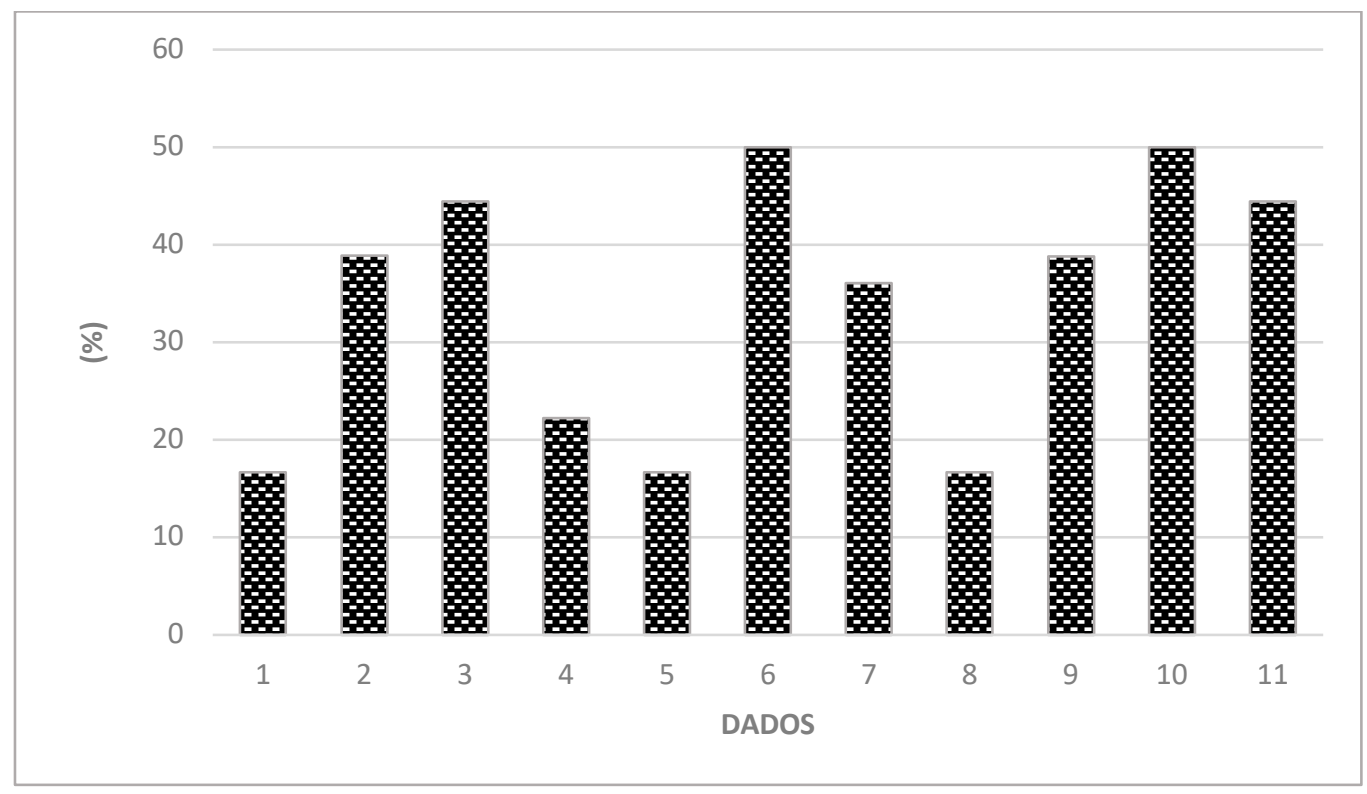

Figura 4 - Porcentagem de municípios, da área de estudo, que informaram possuir dados secundários para serem empregados no diagnóstico dos RSU.

Onde:

1 - Geração e composição dos RSU para os diferentes setores econômicos preponderantes do município; 2 - Diferentes estações do ano; 3 - Datas comemorativas/eventos culturais; 4 - Diferentes tipos de cultura/hábitos de vida locais; 5 - Diferentes tecnologias de tratamento de RSU; 6 - Diferentes tipos de coletas de RSU; 7 - Diferentes tipos de destinação de RSU, por região; 8 - Localizações geográficas territoriais; 9 - Diferentes condições socioeconômicas do território; 10 - Localização geográfica dos estabelecimentos de serviços e comércios locais; 11 - Localização geográfica das indústrias locais.

A percepção da inexistência de dados converge com o conteúdo dos PMGIRS publicados na área de estudo, mas essa não é uma especificidade regional. Se considerados os estudos nacionais e internacionais que abordam a temática, grande parte dos dados sobre RSU são estimados por 
meio de correlações diretas com o uso de escassos dados obtidos em territórios que, na maioria das vezes, não guardam semelhanças socioeconômicas com aqueles que os tomam (KAZA, et al.,2018; SÃO PAULO, 2014; BRASIL, 2012).

No território em estudo, $86 \%$ dos municípios declaram incluir os resíduos de comércio e serviços (RCS) como RSU. Assim sendo, a amostragem dos RSU deve incluir os resíduos gerados nesses estabelecimentos, preferencialmente amostrados separadamente para que os municípios tenham elementos para garantir a correta equiparação quanto ao risco desses resíduos ou atribuir a responsabilidade de manejo aos seus geradores. Além disso, 75\% dos municípios afirmaram coletar os RSU adequadamente, considerada a sua composição, e $42 \%$ o fazem de forma seletiva em secos e úmidos, conforme determinação do decreto 7404/2010 da PNRS.

As variáveis partícipes dos procedimentos de caracterização dos RSU que obtiveram os maiores percentuais de aceitação municipal no território estudado estão apresentadas na Tabela 4.

Tabela 4 - Variáveis do processo de caracterização de RSU, eleitas pelos municípios da região.

\begin{tabular}{|c|c|c|c|}
\hline Variável & Escolha dos municípios & $\begin{array}{l}\text { Porcentagem dos municípios que } \\
\text { fizeram esta escolha (\%) }\end{array}$ & Referência \\
\hline Triagem dos RSU & Manual & 69,4 & DGQA (1989) \\
\hline $\begin{array}{l}\text { Períodos a serem considerados em } \\
\text { uma campanha }\end{array}$ & $\begin{array}{l}\text { Períodos típicos excepcionais } \\
\text { (períodos festivos, datas } \\
\text { comemorativas, eventos } \\
\text { culturais e religiosos, etc.) }\end{array}$ & 63,9 & CE (2004) \\
\hline Divisão em unidades territoriais & $\begin{array}{l}\text { Porções determinadas em } \\
\text { função das condições } \\
\text { socioeconômicas }\end{array}$ & 58,3 & FEAM (2015); CE (2004) \\
\hline $\begin{array}{l}\text { Tipo de preparação da } \\
\text { amostra para triagem }\end{array}$ & Quarteamento & 47,2 & ABNT (2004) \\
\hline $\begin{array}{l}\text { Período de tempo de seleção } \\
\text { de amostras }\end{array}$ & 5 dias & 47,2 & ASTM (1992) \\
\hline $\begin{array}{l}\text { Frequência de repetição } \\
\text { das campanhas }\end{array}$ & A cada 1 ano & 44,4 & CARVALHO (2005) \\
\hline $\begin{array}{c}\text { Tamanho das unidades de } \\
\text { amostragem }\end{array}$ & Porvolume de $1 \mathrm{~m}^{3}$ & 41,7 & CE (2004) \\
\hline Nível de amostragem & No de veículos de coleta & 38,9 & ASTM (1992) \\
\hline Ponto de amostragem & $\begin{array}{l}\text { 1. Contêiner } \\
\text { 2. Pilhas de resíduos }\end{array}$ & 30,6 cada um & ABNT (2004) \\
\hline
\end{tabular}

As escolhas apontadas como preferenciais pelos gestores públicos municipais remetem a procedimentos de amostragem próximos aos que já são executadas no país, e parcialmente contempladas em diferentes proposições metodológicas, conforme referenciado na Tabela 4. Destaca-se que a criação de uma metodologia com os parâmetros sugeridos e, sobretudo, a execução das atividades em conformidade com tal padrão, poderia criar um diferencial de qualidade das informações sem precedentes no país.
Considerada a preleção realizada pelos gestores públicos do território em estudo, a caracterização dos RSU nos municípios deveria ser realizada anualmente por períodos de 5 dias, em amostras realizadas após a coleta pública, planejadas para permitir a distinção territorial das diferentes condições socioeconômicas. As amostras obtidas por meio de quarteamento do volume total coletado deveriam ser triadas manualmente para a determinação da composição gravimétrica e demais análises. Para além desse período também deveria ser realizada a caracterização 
dos RSU em períodos típicos excepcionais, para especificação dos estudos.

Para resíduos com elevada heterogeneidade, como os RSU, a frequência anual de caracterização proposta pode não evidenciar as rápidas transformações de hábitos e costumes da população local, mas essa também é a frequência de amostragem referida por Cruz (2005). A SWA-Tool (CE, 2004) determina a realização de campanhas em diferentes estações do ano, mas, consideradas as condições econômicas brasileiras, entende-se que a realização de uma campanha anual já representaria um significativo avanço em relação à inexistência de série histórica de tais dados.

Os cinco dias de caracterização propostos podem representar a geração de períodos típicos dos territórios, desde que devidamente planejado o período anual de realização da análise. Ressalta-se que, para que os resíduos coletados representem as diferentes condições socioeconômicas vigentes nos territórios, é bem provável que os roteiros de coleta, nos períodos de caracterização, tenham que ser alterados. Para os períodos excepcionais, devem ser realizados planejamentos específicos, consideradas suas características.
O uso de amostras dos RSU coletados, obtidas por meio de quarteamento consecutivo, já é práxis no país, e remonta às instruções publicadas pelo IBAM (2001) e à amostragem para pré-caracterização reportada pela ABNT (2004). Dadas a heterogeneidade e a sazonalidade desses resíduos, a prática pode não comprometer os resultados gerados quando o objetivo da informação estiver atrelado à proposição de políticas públicas associadas ao manejo dos RSU. Em caso de uso dos dados para fins de dimensionamento de unidades de destinação, dados mais específicos podem ser requeridos.

A segregação das amostras manualmente para a determinação da composição gravimétrica dos RSU é a prática mais comum nos processos de caracterização, pois permite maior refinamento e menor custo. No Brasil, onde a integração dos catadores de materiais reutilizáveis e recicláveis é objetivo da PNRS, a triagem manual para fins de caracterização pode ser mais uma forma de inclusão desses trabalhadores (BRASIL, 2010a).

A importância da análise dos parâmetros físico-químicos e biológicos a serem avaliados nas amostras de RSU, percebida pelos gestores públicos do Vale do Paraíba, está mostrada na Fig. 5.

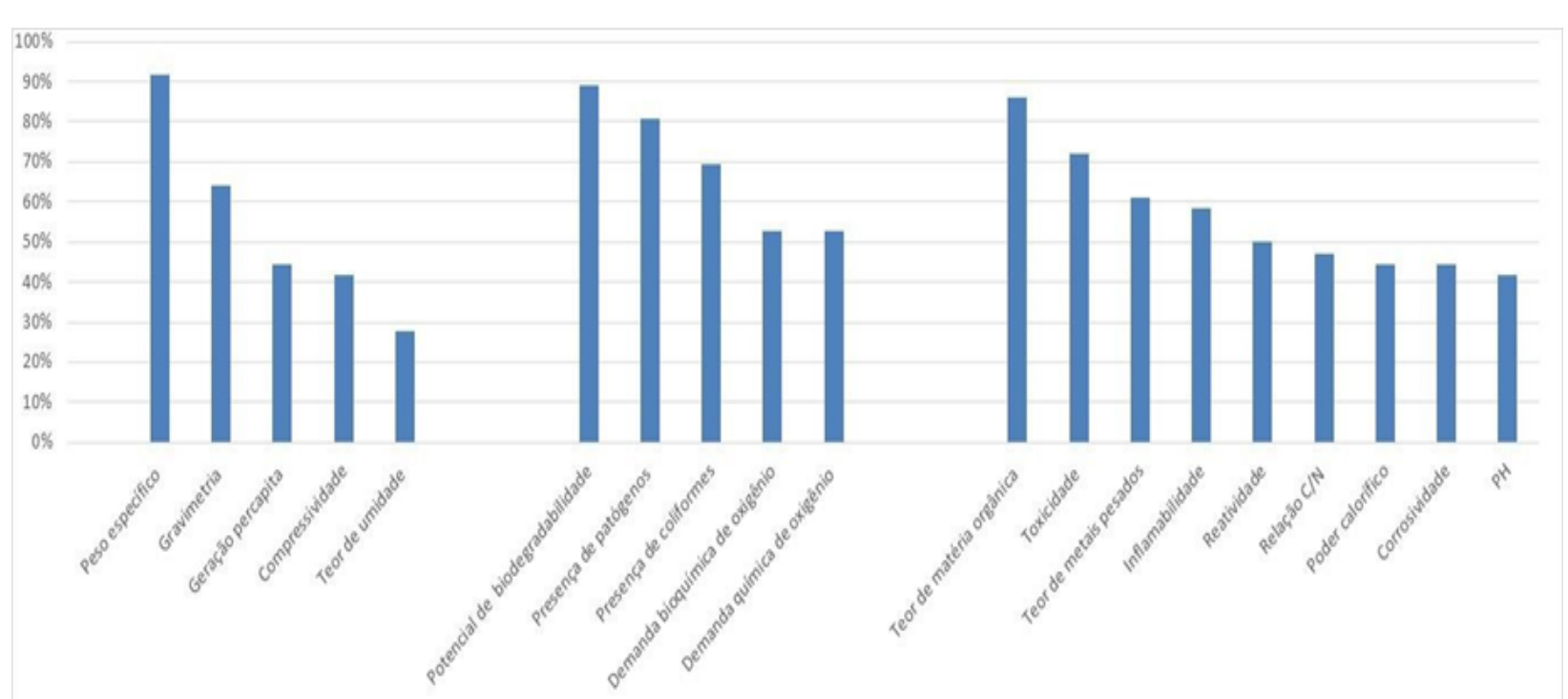

Figura 5 - Importância da análise de parâmetros físico, químicos e biológicos. 
A PNRS, quando aborda a obrigatoriedade de caracterização dos resíduos sólidos, não especifica os parâmetros a serem analisados ou remete às análises de classificação estabelecidas por meio da NBR 10.004 (ABNT, 2004). Por isso, os planos de gestão nacional e dos estados da área de estudo, quando tratam dos RSU, em geral abordam apenas os parâmetros físicos peso específico, gravimetria e geração per capita (BRASIL, 2012; SÃO PAULO, 2014; RIO DE JANEIRO, 2013). As metodologias internacionais utilizadas como base para a construção desse trabalho mostram que nos EUA e na Europa as diretivas também remetem aos mesmos parâmetros físicos (CE, 2004; DGQA, 1989).

O peso específico e a gravimetria, eleitos como mais relevantes pela maioria, são parâmetros físicos já conhecidos e utilizados pelos municípios para decisões relativas à coleta seletiva e de disposição final. No entanto, o teor de umidade da amostra, não percebido como relevante, influencia diretamente o peso específico dos resíduos e é importante parâmetro a ser mensurado nos processos de caracterização.

As escolhas dos parâmetros químicos realizadas pelos gestores municipais denotam a preocupação com os riscos associados à saúde humana e com o meio ambiente, associados à destinação dos RSU, já abarcados no país pela NBR 10.004/2004. A escolha da relação C:N, no entanto, remete a uma tendência de serem conside- rados os processos biológicos para o tratamento dos elevados percentuais de matéria orgânica presente nesses resíduos. A análise desse parâmetro pode também conduzir a melhores estimativas de emissões gasosas em aterros.

A inexistência de processos térmicos para tratamento dos RSU na região pode influenciar a não preleção do parâmetro "poder calorífico". No entanto, considerados os novos instrumentos legais sobre a temática, vigentes no país, esse pode ser um parâmetro relevante a ser incluído no processo de caracterização.

As análises biológicas percebidas como relevantes pelos gestores também remetem ao tratamento das porções de material orgânico presentes nos RSU e aos riscos associados ao manejo desses resíduos. Vale destacar que novas pesquisas devem ser conduzidas no intuito de avaliar, de forma expedita, a presença de organismos patogênicos em resíduos sólidos.

Para a equiparação das campanhas de amostragem, também é fundamental que a planilha de composição mínima adotada para a caracterização física dos RSU seja padronizada. A Fig. 6 mostra os resultados dos tipos de resíduos entendidos como passíveis de serem segregados no ato da caracterização pelos gestores municipais do território em estudo, em padrão de cores semelhante ao adotado para a coleta seletiva dos respectivos materiais. 


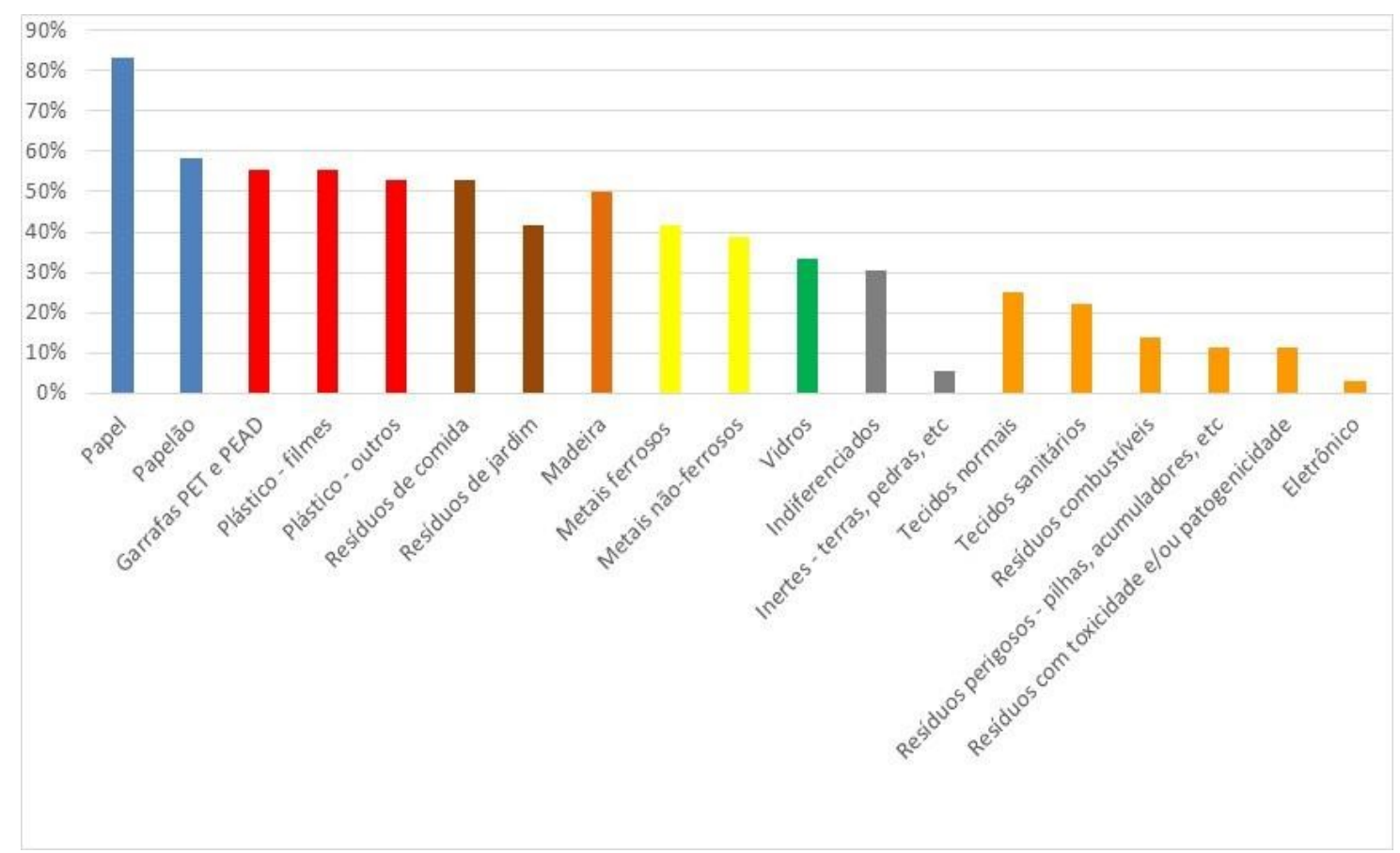

Figura 6 - Categorias de segregação de RSU escolhidas pelos municípios.

As categorias eleitas pelos municípios são convergentes com aquelas verificadas nos planos estaduais de resíduos dos estados pertencentes à bacia em estudo. Considerando esses dados, a especificação mais detalhada para a análise da composição gravimétrica dos RSU da região em estudo deveria ser realizada em 14 categorias, a saber: Material Orgânico, Vidro (Escuro e Claro), Papelão, Papel, Borracha, PET (Branco e Verde), Plástico (Filme e Duro), Metal (Ferroso e Não ferroso), Madeira e Outros. (SÃO PAULO, 2014; RIO DE JANEIRO, 2013). Essas categorias podem ser entendidas como subdivisões e/ou renomeação daquelas reportadas em publicações internacionais, que categorizam os resíduos em: alimentos e verdes, metal, papel e papelão, plástico, madeira, vidro e outros (KAZA, et al., 2018).

A DGQQA (1989) estabelece a separação dos RSU em quinze categorias, a saber: Papel e cartão (embalagens e outros); Vidros (embalagens e outros); Plástico (embalagens rígidas, filme e outros); Metais (embalagens e outros); Materiais fermentáveis; Têxteis; Madeira; Finos (<20 mm); Pilhas e Outros. Já o Programa-Quadro da Comissão Europeia (CE, 2004) mostra um catálogo de triagem da metodologia contendo 12 categorias primárias obrigatórias com os itens: orgânicos, madeira, papel/cartão, plásticos, vidro, têxteis, metais, resíduos domésticos perigosos, produtos complexos, inertes, outras categorias e finos; e recomenda também a adição de outras 35 categorias secundárias que podem oferecer mais detalhes sobre os RSU.

As categorias eleitas pelos municípios são convergentes com aquelas verificadas nos planos estaduais de resíduos dos estados pertencentes à bacia em estudo. Considerando esses dados, a especificação mais detalhada para a análise da composição gravimétrica dos RSU da região em estudo deveria ser realizada em 14 categorias, a saber: Material Orgânico, Vidro (Escuro e Claro), Papelão, Papel, Borracha, PET (Branco e Verde), Plástico (Filme e Duro), Metal (Ferroso e Não ferroso), Madeira e Outros (SMA, 2014 \& Rio de Janeiro, 2013). 
As escolhas realizadas pelos gestores municipais nem sempre correspondem à disponibilidade de recursos nos territórios para a realização das ati- vidades, conforme pode ser observado no gráfico da Fig. 7, que mostra a disponibilidade de recursos físicos e de pessoal.

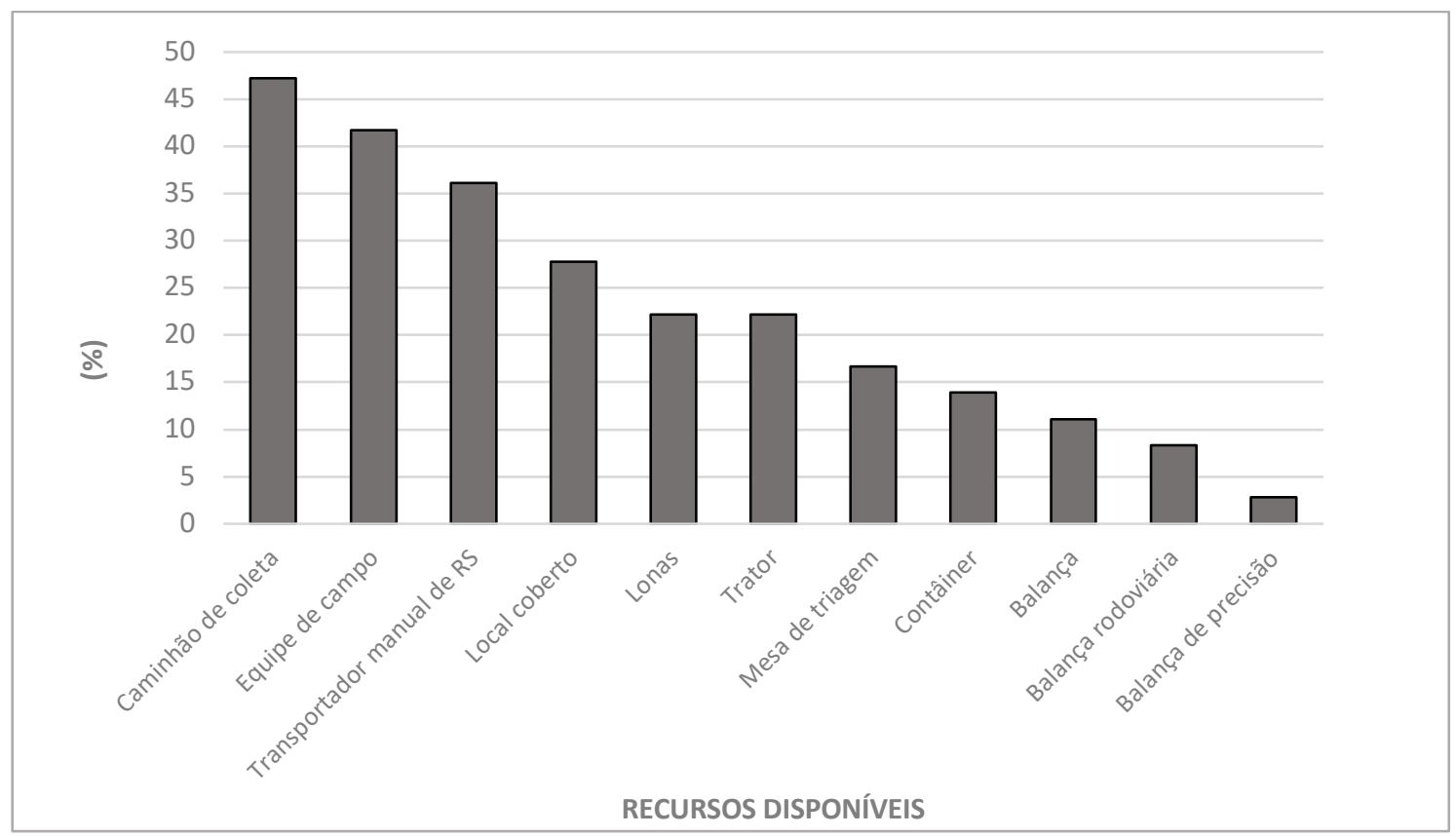

Figura 7 - Recursos físicos e de pessoal para a caracterização de RSU já existentes.

A inexistência de recursos nos territórios locais para caracterização dos RSU precisa ser avaliada individualmente, pois, conforme pode ser observado, alguns itens inerentes à coleta de RSU existentes em todos os municípios da região de estudo são informados como não disponíveis. Possivelmente, ao responder ao quesito, os gestores se referiram aos recursos sob sua responsabilidade, e não consideraram a possibilidade de locação e empréstimos dentro do próprio território.

Convém que as análises sejam realizadas em laboratórios acreditados e que as amostras sejam devidamente coletadas e preservadas pela equipe de campo. No território em estudo existem laboratórios privados que poderiam prestar os serviços e instituições de ensino públicas que também podem ser acionadas para prestação de apoio.

Considerado o impacto direto do manejo dos resíduos sólidos na qualidade de águas da bacia hidrográfica do rio Paraíba do Sul, é mister inferir que, em caso de demanda real de recursos para tal fim, o CEIVAP poderia ser um dos órgãos acessados, já que desde 2013 vem invitando recursos para garantir a elaboração dos PMGIRS para propiciar a correta destinação dos RSU.

As precauções de segurança devem sempre ser observadas na amostragem de resíduos. 0 responsável pela amostragem deve estar atento às possíveis características perigosas dos resíduos e dos locais de coleta (ABNT NBR 10007:2004) e prover a revisão dos perigos e procedimentos com o pessoal de operação e triagem antes de serem iniciados os trabalhos (ASTM Método D 5231 - 92). A Fig. 8 mostra os recursos associados à segurança do processo de caracterização, identificados como existentes por percentuais de municípios pesquisados. 


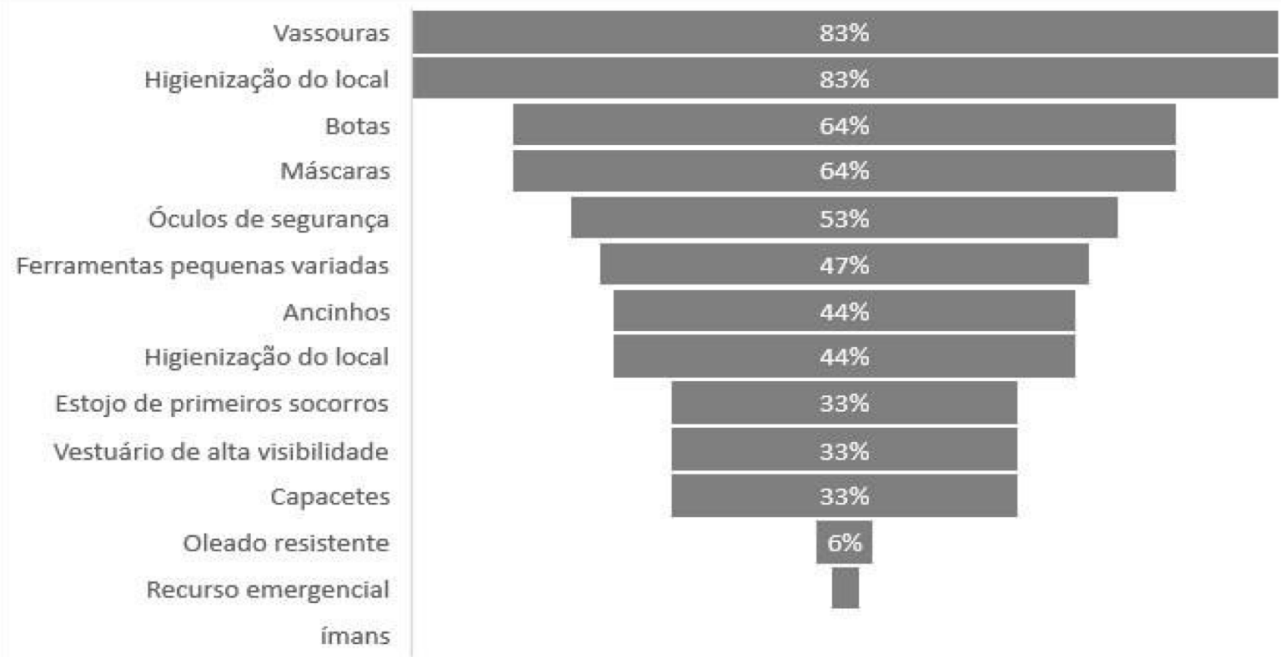

Figura 8 - Recursos associados à segurança da caracterização de RSU já existentes.

Vale destacar que, segundo a NBR 10.007 (ABNT, 2004), quando for detectada a possibilidade de a amostragem ser de alto risco, o técnico de amostragem deve informar ao responsável pela elaboração do plano de amostragem a necessidade da reavaliação do plano, solicitando, se necessário, a presença de entidades especializadas para a manipulação do material. Ressalta-se também que grande parte dos equipamentos de proteção individual e coletiva requeridos para o manejo dos RSU, durante o período de caracterização, são semelhantes aos que asseguram os trabalhadores no manejo dos RSU nas ações de coleta, transporte e destinação desses resíduos realizadas cotidianamente nos municípios (ABNT, 1993).

Os demais materiais demandados durante o processo de caracterização dos RSU, tais como ancinhos e ferramentas de pequeno porte, em geral já estão disponíveis nas secretarias responsáveis pela manutenção dos espaços públicos dos territórios municipais e, eventualmente, podem ser alocados temporariamente para o processo de caracterização. De qualquer modo, possuem baixo custo, e caso venham a ser adquiridos para uso exclusivo do processo de caracterização, podem ser armazenados para uso futuro.

\section{CONSIDERAÇÕES FINAIS}

Dos resultados dessa pesquisa, infere-se que são escassas as metodologias de caracterização de RSU no Brasil e no mundo, e as existentes não guardam semelhanças entre si que permitam a equiparação dos resultados para grupos semeIhantes de população. Essa escassez pode ser decorrente da alta complexidade de serem gerados dados de qualidade relativos à geração e composição dos RSU, assim como da própria ausência de normas sobre a temática.

Em linhas gerais, as metodologias existentes apresentam apenas a caracterização física dos RSU. No entanto, as caracterizações química e biológica possuem igual importância, fazendose necessários estudos mais detalhados e elaboração de outras propostas metodológicas que considerem a avaliação expedita desses parâmetros. No Brasil, embora a caracterização dos RS figure como conteúdo mínimo dos planos de gestão e gerenciamento de resíduos sólidos, a inexistência de especificação sobre o 
tipo de caracterização a ser realizada pode corroborar para que apenas a caracterização física dos RSU seja realizada.

A necessidade de pacto nacional por uma metodologia de caracterização dos RSU é notória, principalmente se considerados os regramentos legais vigentes no Brasil. Nesse sentido, os resultados dessa pesquisa evidenciam que, ao elaborar uma metodologia de caracterização dos RSU é necessário, além de considerar os parâmetros e representatividades das amostras, que haja viabilidade de serem incorporadas as características locais, para que a metodologia atenda fidedignamente às demandas dos territórios associadas a seus padrões de geração e composição dos RSU. Nesse sentido, os dados secundários devem ser complementados com dados primários dos locais avaliados e a transposição de dados deve ser evitada.

Com relação aos requisitos aplicáveis à caracterização dos RSU, na bacia do rio Paraíba do Sul, entende-se que os dados produzidos por essa pesquisa se prestarão à elaboração de uma metodologia com elevado grau de especificidade e que poderá nortear os trabalhos a serem realizados no território. Para que a metodologia tenha maior aceitação e confiabilidade, outros atores sociais também devem participar de sua construção, tais como: a comunidade científica, os geradores e os trabalhadores em atividades de manejo de RSU.

\section{CONTRIBUIÇÃO DOS AUTORES}

Conceitualização: VIEIRA DCR; Metodologia: VIEIRA DCR; e FIORE, FA; Investigação: VIEIRA DCR; Redação - Primeira versão: VIEIRA DCR; e FIORE, FA; Redação - Revisão \& Edição: VIEIRA DCR; e FIORE, FA.; Aquisição de Financiamento: VIEIRA DCR; e FIORE, FA; Recursos: VIEIRA DCR; e FIORE, FA; Supervisão: FIORE, FA.

\section{AGRADECIMENTOS}

Agradecemos à FAPESP pelo apoio concedido à pesquisa (Processo FAPESP n. ${ }^{\circ}$ 2017/26098-8).

Agradecemos ao apoio institucional da AGEVAP e à Engenheira Amanda Lima do DEA/ICT Unesp.

\section{REFERÊNCIAS}

ASTM INTERNATIONAL. Sociedade Americana de Testes e Materiais Internacional. Método de teste padrão para determinação da composição de resíduos sólidos municipais não processados - D 5231/92. Standard Test Method for Determination of the Composition of Unprocessed Municipal Solid Waste. Reaprovado em 2003. Disponível em: <http://dl.mozh.org/uploads/141642738205921.pdf> Acesso em Outubro de 2017.

ASSOCIAÇÃO BRASILEIRA DE NORMAS TÉCNICAS. NBR 10007: Amostragem de resíduos sólidos. Rio de Janeiro: Moderna, 2004. 21 p.

ASSOCIAÇÃO BRASILEIRA DE NORMAS TÉCNICAS. NBR 12980: Coleta, Varrição e acondicionamento de resíduos sólidos urbanos. Rio de Janeiro, 1993.

BARBOSA, L. T. Gerenciamento de resíduos sólidos urbanos no norte de Minas Gerais: estudo relativo à implantação de unidades de reciclagem e compostagem a partir de 1997. Dissertação (Mestrado). Escola de Engenharia da UFMG. Belo Horizonte, 2004.

BRASIL. Lei Federal no 12.305, de 2 de agosto de 2010. Institui a Política Nacional de Resíduos Sólidos; altera a Lei no 9. 605, de 12 de fevereiro de 1998; e dá outras providências. Diário Oficial da União, Brasília, DF, 3 ago. 2010.

CALIJURI, M. C. (coord.); CUNHA, D. G. F.(coord.). Engenharia Ambiental: conceitos, tecnologia e gestão. Rio de Janeiro: Elsevier, 2013.

CAMPOS, H.K.T. Renda e evolução da geração per capita de resíduos sólidos no Brasil. Artigo Técnico. Eng. Sanit. Ambient. | v.17 n.2 | abr/jun 2012 | 171-180. Distrito Federal, Brasília. (https:// doi.org/10.1590/S1413-41522012000200006).

CANTARELLA, H; QUAGGIO, J. A.; RAIJ B. van. Determinação da matéria orgânica. In: RAlJ, B. van; ANDRADE, J. C. de; CANTARELLA, H.; QUAGGIO, J. A. (Ed.). Análise Química para Avaliação da Fertilidade de Solos Tropicais. Campinas: Instituto Agronômico, 2001. cap. 9, p.173-180.

CARVALHO, E. M. F. D. B. Metodologias para a quantificação e caracterização física dos resíduos sólidos urbanos. Dissertação (Mestrado em Engenharia Sanitária) - Faculdade de Ciências e Tecnologia da Universidade Nova de. Departamento de Ciências e Engenharia do Ambiente. Lisboa, 2005. 
CE. COMISSÃO EUROPEIA. Metodologia para Análise de Resíduos Sólidos. Methodology for the Analysis of Solid Waste (SWA-Tool). Elaborado pelo Consórcio SWA-Tool. Austria, 2004. Disponível em <https://www.wien.gv.at/meu/fdb/pdf/swa-tool-759-ma48.pdf> Acesso em outubro de 2017.

CEIVAP. Relatório Técnico. AGVP_PARAIBA_PRH -PT_R01. Complementação e finalização do plano integrado de recursos hídricos da bacia hidrográfica do rio paraíba do sul - PIRH-PS e elaboração dos planos de recursos hídricos das bacias hidrográficas afluentes. Março, 2018.

CRUZ, M. L. F. R.. A Caracterização de Resíduos Sólidos no Âmbito da sua Gestão Integrada. Dissertação (Mestrado). Braga Portugal, 2005.

CERVO, A. L; BERVIAN, P. A. Metodologia científica. 5. ed. São Paulo: Prentice Hall, 2002.

DE MELO, E. S. R. L. Análise de Biodegradabilidade dos materiais que compões os Resíduos Sólidos Urbanos através de Ensaios BMP. Dissertação (Mestrado em Engenharia Civil). Universidade Federal de Pernambuco. Recife, 2010.

DGQA (1989). Documento Técnico n¹ - Resíduos Sólidos Urbanos - Quantificação e caracterização. Metodologia. Direcção-Geral da Qualidade do Ambiente. Lisboa.

DRA. Direção Regional do Ambiente. Campanha de Quantificação e Caracterização de Resíduos Sólidos Urbanos. Região Autônoma de Açores. Disponível em: < http://www. azores.gov.pt/NR/rdonlyres/D72E8A2B-5DBF-4BFE-8D35-BBF4CD596243/3641/CampanhadeQuantifica\%C3\%A7\%C3\%A3oeCaracteriza\%C3\%A7\%C3\%A3odeRSU.pdf> Acesso em outubro de 2017.

FALCÃO, A. A. Análise química de resíduos sólidos para estudos agroambientais. Campinas, SP: [s.n], 2005.

FEAM. Fundação Estadual do Meio Ambiente. Metodologia simplificada de caracterização de resíduos sólidos urbanos para municípios do Estado de Minas Gerais. Minas Gerais, 2015. Disponível em: <http://www.feam.br/component/content/article/13textoinformativo/1307-geracao-per-capita-e-composicao-gravimetrica-dos-rsu-nos-municipios-de-minas-gerais-> Acesso em dezembro de 2017.

FEAM. Estudo Gravimétrico de Resíduos Sólidos Urbanos. Cartilha de Orientações. Belo Horizonte, 2019.

FREITAS, H; OLIVEIRA, M; SACCOL, A. Z; MOSCAROLA, J. Método de Pesquisa Survey. Revista de Administração, São Paulo v.35, n.3, p.105-112, julho/setembro, 2000.

GERHARD, T. T; SILVEIRA, D. T. Métodos de pesquisa. Coordenado pela Universidade Aberta do Brasil- UAB/UFRGS e pelo Curso de Graduação Tecnológica - Planejamento e Gestão para o Desenvolvimento Rural da SEAD/UFRGS. - Porto Alegre: Editora da UFRGS, 2009. (ISBN 978-85-386-0071-8)
IBGE. INSTITUTO BRASILEIRO DE GEOGRAFIA ESTATísTICA. Pesquisa de Informações Básicas Municipais - MUNIC. Municípios que declararam possuir Plano de Gestão Integrada de Resíduos Sólidos. 2013.

IPEA. INSTITUTO DE PESQQUISA ECONÔMICA APLICADA. Diagnóstico dos Resíduos Sólidos Urbanos, Relatório de pesquisa. Brasília, 2012. Disponível em: <http://www.ipea.gov.br/agencia/ images/stories/PDFs/relatoriopesquisa/121009_relatorio_residuos_solidos_urbanos.pdf> Acesso em 13 de dezembro de 2017.

IGARATÁ. Plano Municipal de Gestão Integrada de Resíduos Sólidos de Rio Preto. Igaratá, São Paulo. 2012.

JACAREÍ. Plano Municipal de Gestão Integrada de Resíduos Sólidos de Jacareí. Jacareí, São Paulo. 2017.

LOBATO, K.C.D. \& LIMA, J.P. Mapeamento de processos de seleção de resíduos sólidos urbanos. Eng Sanit Ambiental | v.15 n.4 | out/ dez 2010 | 347-356.

PROTASIO, F. N. M. Caracterização do Resíduo Sólido Urbano do Aterro Controlado de Jardim Gramacho. Trabalho de iniciação científica. Departamento de Engenharia Civil da Puc Rio. Rio de Janeiro, 2013.

MINAS GERAIS. Lei $\mathbf{n}^{\circ} \mathbf{1 8 . 0 3 1}$ de 12 de janeiro de 2009. Institui a política estadual de resíduos sólidos.

MINISTÉRIO DO MEIO AMBIENTE. ICLEI - Brasil. Planos de gestão de resíduos sólidos: manual de orientação. Brasília, 2012

MINISTÉRIO DO MEIO AMBIENTE. ICLEI - Brasil. Guia para Elaboração dos Planos de gestão de resíduos sólidos: manual de orientação. Brasília, 2011.

MINISTÉRIO DO MEIO AMBIENTE - Planos Municipais de Gestão Integrada de Resíduos Sólidos. 2018. Municípios que possuem PMGIRS. Disponível em: < https://www.mma.gov.br/cidades-sustentaveis/residuos-solidos/instrumentos-da-politica-de-residuos/planos-municipais-de-gest\%C3\%A3o-integrada-de-es\%C3\%ADduoss\%C3\%B3lidos>. Acesso em agosto de 2019.

NASCIMENTO, J. C. F. Comportamento mecânico de resíduos sólidos urbanos. Dissertação (Mestrado em Geotecnia) - Escola de Engenharia de São Carlos da Universidade de São Paulo, São Carlos, 2007.

RIO DE JANEIRO. Lei Estadual no 4191 de 30 de setembro de 2003. Institui a política estadual de resíduos sólidos.

RIO DE JANEIRO. Plano Estadual de Resíduos Sólidos do Rio de Janeiro. Convênio SRHU/MMA nº 010/2007 - Elaboração do Plano de Gestão de Resíduos Sólidos do Estado do Rio de Janeiro. Rio de janeiro, 2013.

RIO PRETO. Plano Municipal de Gestão Integrada de Resíduos Sólidos de Rio Preto. Rio Preto, MG, 2014. 
ROMANI, A. P; SEGALA, K. Planos de resíduos sólidos: desafios e oportunidades no contexto da Política Nacional de Resíduos Sólidos. Rio de Janeiro: IBAM, 2014.

RUTKOWSKI, E. W; OLIVEIRA, J.F.D; F.A. FIORE. Resíduos Sólidos Municipais: Métodos de Análise de Composição Gravimétrica Estudo de Caso: GAEMA Campinas, São Paulo, Brasil. In: Congresso Interamericano da AIDIS. Cartagena, Colômbia, 2016. Anais...

SIMAS, A.L. et al. n [recurso eletrônico] / Secretaria do Meio Ambiente do Estado de São Paulo, Coordenadoria de Planejamento Ambiental, CETESB; - 1a ed. - São Paulo: SMA, 2014. 1 arquivo de texto (350 p.): il. color., PDF; $160 \mathrm{MB}$.

SÃO PAULO. Lei estadual $n^{\circ} 12.300$ de 16 de março de 2006. Institui a política estadual de resíduos sólidos.
SILVA, H. V. O. O Uso de Indicadores Ambientais para Aumentar a Efetividade da Gestão Ambiental Municipal. Universidade Federal do Rio de Janeiro, COPPE (tese), 2008.

SOARES, E. L. S. F. Estudo da caracterização gravimétrica e poder calorífico dos resíduos sólidos urbanos. Dissertação (Mestrado em Engenharia Civil) - Universidade Federal do Rio de Janeiro. Rio de Janeiro, 2011.

SOUZA, J. A. R. S; MOREIRA, D. A; GUIMARÃES, G. I; CARVALHO, W. B. Caracterização dos resíduos sólidos urbanos em Urutaí, GO. Multi-Science Journal 2015; 1(1):79-83. Goiás, 2015. (https:// doi.org/10.33837/msj.v1i1.52)

YIN, R. K. Pesquisa qualitativa do início ao fim [recurso eletrônico] / Robert K. Yin ; tradução: Daniel Bueno ; revisão técnica: Dirceu da Silva. - Porto Alegre: Penso, 2016. ePUB. 